\title{
Snail1 induces epithelial-to-mesenchymal transition and tumor initiating stem cell characteristics
}

\author{
Hien Dang, Wei Ding, Dow Emerson and C Bart Rountree*
}

\begin{abstract}
Background: Tumor initiating stem-like cells (TISCS) are a subset of neoplastic cells that possess distinct survival mechanisms and self-renewal characteristics crucial for tumor maintenance and propagation. The induction of epithelial-mesenchymal-transition (EMT) by TGF $\beta$ has been recently linked to the acquisition of TISC characteristics in breast cancer. In HCC, a TISC and EMT phenotype correlates with a worse prognosis. In this work, our aim is to elucidate the underlying mechanism by which cells acquire tumor initiating characteristics after EMT.

Methods: Gene and protein expression assays and Nanog-promoter luciferase reporter were utilized in epithelial and mesenchymal phenotype liver cancer cell lines. EMT was analyzed with migration/invasion assays. TISC characteristics were analyzed with tumor-sphere self-renewal and chemotherapy resistance assays. In vivo tumor assay was performed to investigate the role of Snail1 in tumor initiation.

Conclusion: TGF $\beta$ induced EMT in epithelial cells through the up-regulation of Snail 1 in Smad-dependent signaling. Mesenchymal liver cancer post-EMT demonstrates TISC characteristics such as tumor-sphere formation but are not resistant to cytotoxic therapy. The inhibition of Snail1 in mesenchymal cells results in decreased Nanog promoter luciferase activity and loss of self-renewal characteristics in vitro. These changes confirm the direct role of Snail1 in some TISC traits. In vivo, the down-regulation of Snail1 reduced tumor growth but was not sufficient to eliminate tumor initiation. In summary, TGF $\beta$ induces EMT and TISC characteristics through Snail 1 and Nanog upregulation. In mesenchymal cells post-EMT, Snail1 directly regulates Nanog expression, and loss of Snail1 regulates tumor growth without affecting tumor initiation.
\end{abstract}

\section{Background}

Tumor initiating stem-like cells (TISCs), also defined as cancer stem cells, are a subpopulation of neoplastic cells that possess distinct survival and regeneration mechanisms important for chemotherapy resistance and disease progression $[1,2]$. By definition, TISCs possess stem cell features including resistance to apoptosis and selfrenewal [3-5]. After their initial discovery and characterization within hematological malignancies [6,7], TISCs have now been described in many different malignancies including hepatocellular carcinoma (HCC) [8,9]. Further evidence supports that $\mathrm{HCC}$ arises as a direct consequence of dysregulated proliferation of hepatic

\footnotetext{
* Correspondence: crountree@hmc.psu.edu Department of Pediatrics and Pharmacology, The Pennsylvania State University, College of Medicine, Penn State Children's Hospital, Hershey, Pennsylvania, USA
}

progenitor cells $[10,11]$. Transcriptome analysis of HCC demonstrated that a progenitor-based (TISC-phenotype) expression profile is associated with a poor prognosis compared to differentiated tumors (hepatocyte-phenotype) [12-14].

Resistance to therapy and metastatic disease are two factors that correlate a TISC-phenotype HCC with poor survival. TISCs are hypothesized to be the source of metastatic lesions, as a tumor-initiating cell [15]. Although this hypothesis remains controversial, recent work establishes a connection between epithelialmesenchymal-transition (EMT) and a TISC-phenotype $[16,17]$. EMT is a critical developmental process that plays a central role in the formation and differentiation of multiple tissues and organs. During EMT, epithelial cells lose cell-cell adhesion and apical-polarity, and 
acquire mesenchymal features, such as motility, invasiveness, and resistance to apoptosis [18].

One of the key hallmarks of EMT is loss of E-cadherin, a cell-adhesion protein that is regulated by multiple transcription factors including Snail, Slug, and Twist. These transcription factors act as E-box repressors and block E-cadherin transcription [18]. In cancer biology, EMT is one mechanism to explain the invasive and migratory capabilities that epithelial carcinomas acquire during metastasis $[19,20]$. In HCC, increased expression of the E-cadherin repressors Twist and Snail correlates with poor clinical outcomes [21]. In breast cancer, EMT is associated with the acquisition of a TISC CD44 ${ }^{+} / \mathrm{CD} 24^{\text {low }}$ phenotype $[17,22]$.

One of the major inducer of EMT is transforming growth factor- $\beta$ (TGF $\beta$ ), a multifunctional cytokine that regulates cell proliferation, differentiation and apoptosis [23]. In early stages of carcinogenesis, TGF $\beta$ serves as a tumor suppressor by inhibiting cell growth, and in later stages of disease, tumor cells escape this growth inhibition. As late stage cancer tends to be resistant to TGF $\beta$ driven growth arrest signals and as TGF $\beta$ is a known inducer of EMT, TGF $\beta$ is proposed to be a facilitator of cancer progression during late stage disease [24-26]. TGF $\beta$ induces EMT by up-regulating Snail1 via the Smad-dependent pathways [27]. Mishra and colleagues have reviewed the complexity of TGF $\beta$ signaling during hepatocarcinogenesis, specifically as related to $\beta 2-\mathrm{Spec}-$ trin loss and stem cell malignant transformation [15,28-30].

As additional evidence linking EMT to TISCs, TGF $\beta$ regulates Nanog expression, a transcription factor that contributes to self-renewal and cell fate determination in embryonic stem cells [31,32]. In prostate cancer, increased Nanog expression is implicated in tumor progression, and the co-expression of Nanog and Oct4 promotes tumor-sphere formation $[4,33,34]$. In colon cancer, increased Snail1 expression correlates to increased Nanog expression [35]. In human HCC cell lines, TGF $\beta$ regulates $C D 133$ expression, a marker of TISCs, through induction of epigenetic modifications of the $C D 133$ promoter $[23,36]$.

Thus, several studies have demonstrated that TGF $\beta$ drives EMT through Snail1 up-regulation, and other studies have correlated EMT to the acquisition of TISC characteristics. What is lacking is an understanding of the mechanism of how liver cancer cells acquire TISC characteristics through EMT. Our hypothesis is that mesenchymal cells acquire TISC traits after EMT through Snail1-dependent mechanisms. In this report, we demonstrate that mesenchymal liver cancer cells (post-EMT) possess several TISC characteristics compared to epithelial cells. TGF $\beta$ induces EMT and TISC characteristics in epithelial cells through Snail1. In mesenchymal cells, knock-down of Snail1 results in loss of Nanog and reduction of TISC traits. In vivo studies demonstrate that Snail1 regulates tumor growth but does not fully control tumor initiation.

\section{Methods}

\section{Cell Culture}

Epithelial and mesenchymal murine liver cancer cells were cultured in Dulbecco's modified Eagle's medium (DMEM)/F12 (Sigma) supplemented with 10\% fetal bovine serum as described [37]. The human HCC cell line Huh7 was provided by Jianming Huh, Penn State College of Medicine and cultured as described [36,38]. The human HCC The human HCC cell lines MHCC97L were provided by Xinwei Wang, National Cancer Institute, under agreement with the Liver Cancer Institute, Zhongshan Hospital, Fudan University, Shanghai, China and cultured as described [39].

\section{Transfections}

For Snail1 transient knockdown, cells were transfected with 100 pM of Snail1 Stealth siRNA (Invitrogen) using Lipofectamine 2000 (Invitrogen). For Smad signaling inhibition, cells were transfected with 2 ug of DNA using Fugene 6 (Roche). To generate Snail1 knockdown stable transfectants, mesenchymal cells were transfected with Snail1 Mission shRNA lentivirus (Sigma) and selected with $2 \mathrm{ug} / \mathrm{ml}$ of puromycin.

\section{Luciferase Assay}

pCMV5-Smad7-HA (Plasmid 11733), pRK-Smad3 $\Delta$ C (Plasmid 12626), and Nanog-Luc (Plasmid 16337) were provided by Addgene. Cells were plated in 12 well plates, incubated overnight, and transfected with the Nanog-Luc plasmid and Renilla for 24 hours (4:1 NanogLuc:Renilla ratio). Cells were washed with $1 \times \mathrm{PBS}$, serum free starved for 2 hours, and treated with $5 \mathrm{ng}$ / $\mathrm{ml}$ of TGF $\beta$ for 24 hours. Following cell lysis, luciferase activity was measured using the Dual Luciferase Assay Kit (Promega) and a Sirius Luminometer V3.1 (Zylux). Luciferase reading light units (RLU) were normalized to Renilla RLU and a fold change was calculated.

\section{qRT-PCR}

Trizol (Invitrogen) was used to isolate total RNA from cells according to manufacturer's protocol. Isolated RNA was quantified using the ND-1000 spectrophotometer (NanoDrop) and complementary single strand DNA was synthesized using the Omniscript RT Kit according to the manufacturers protocol (Qiagen). qPCR was performed using Taqman Gene Expression Assays and ABI-Prism 7700 Thermal Cycler (Applied Biosystems). Normalization was performed using $\beta$-actin or Gapdh as an endogenous control and relative gene 
expression was calculated using the comparative $2^{(-\Delta \Delta \mathrm{Ct})}$ method with SDS 2.2.2 software [36].

\section{Cell Viability Assays}

Cell viability was performed using the XTT (2,3-bis(2methoxy-4-nitro-5-sulfophenyl)-2H-tetrazolium-5-carboxanilide) kit (Trevigen) according to the manufacturer's protocol. $5 \times 10^{3}$ cells were plated in 96-well plates, incubated for 24 hours at $37^{\circ} \mathrm{C}$, and treated with specified agents at defined time points.

\section{Western Blot Analysis}

Cells were washed twice with ice cold 1XPBS and cell lysates were harvested by the addition of lysis buffer (40 $\mathrm{nM}$ Tris [pH 7.4], $150 \mathrm{mM} \mathrm{NaCl}, 10 \mathrm{mM}$ ethylene diamine tetraccetic acid, $10 \%$ glycerol, $1 \%$ Triton X-100, 10 $\mathrm{mM}$ glycerophosphate, $1 \mathrm{mM} \mathrm{Na3VO} 4,1 \mathrm{mM}$ phenylmethylsulfonyl fluoride) supplemented with protease inhibitor cocktail tablets (Roche). BCA protein assay (Thermo Fisher Scientific) was used to determine protein concentration as described [40]. 30 ug of protein lysates were separated on a NuPAGE 4-12\% Bis-Tris Gel (Invitrogen) and the separated proteins were transferred onto a polyvinylidene difluoride membrane (Invitrogen). After blocking for $60 \mathrm{~min}$ with 5\% non-fat dry milk, membranes were incubated with the primary antibody overnight at $4^{\circ} \mathrm{C}$ followed by incubation with corresponding secondary antibody for $60 \mathrm{~min}$ at room temperature. The membranes were developed using enhance chemiluminescence solutions (Thermo Fisher Scientific) [41].

\section{Cell Migration Assay}

The capability of tumor cell migration was assessed using a wound-healing assay. Confluent cell monolayers were manually wounded by scraping the cells with a $1,000 \mu \mathrm{L}$ pipette tip down the center of the well. The cell culture medium was replaced and migration was assessed at 24 hours [37].

\section{Matrigel Invasion Assay}

Cell invasion was assessed using 6-well Transwell permeable inserts with $8-\mu \mathrm{m}$ pores (Corning) [37]. In brief, $1 \times$ $10^{5}$ cells were cultured in a serum-free DMEM/F12 medium in an insert coated with Matrigel (BD). Below the insert, the chamber of 6-well plates contained DMEM/ F12 supplemented with 10\% FBS. Cells were incubated in a $37^{\circ} \mathrm{C}$ incubator for 48 hours and the number of cells that invaded across the membranes and fallen onto the bottom of the plate was counted.

\section{Transcriptome analysis}

Using the cell lines from the liver specific $\mathrm{Pten}^{-/-}$model described [37] P2E (epithelial) and P2M (mesenchymal) messenger RNA were analyzed using an Illumina mouse gene chip according to the manufacturer's protocol and as described [37]. Housekeeping genes were used as standards to generate expression levels, and data analysis was conducted using 1.4-fold or greater change in expression with $\mathrm{p}<0.05$ as significant. The full complement of the expression data is available at http://www. ncbi.nlm.nih.gov/geo (Accession number GSE18255).

\section{Spheroid Formation Assay}

The capability of self-renewal was assessed using Corning Ultra-Low Attachment Surface (Corning). $5 \times 10^{3}$ cells were seeded and incubated in a cell culture incubator for 1 week in DMEM/F12 supplemented with 10\% FBS or serum free medium and phase-contrast images were obtained.

\section{In vivo tumor growth assay}

Cells were counted with trypan blue exclusion and suspended in a 1:3 dilution of Matrigel (Matrigel:DMEM/ F12 supplemented with $10 \%$ FBS) [36]. $1 \times 10^{4}$ and $1 \times$ $10^{5}$ cells $/ 50 \mu \mathrm{L}$ were injected subcutaneously into 10 week-old nude mice. Caliper measurements of tumor volume (length $x$ width $\times$ height) were conducted every 2 days. After 3 weeks, mice were sacrificed for tumor analysis. All procedures were in compliance with our institution's guidelines for the use of laboratory animals and approved by the Penn State College of Medicine Institutional Animal Care and Use Committee.

\section{Statistical Analysis}

Microarray statistical analysis was performed as describe [37]. Student t test was used comparing two groups. One-way ANOVA was used comparing multiple groups followed by Tukeys post-hoc test. All analysis with a $\mathrm{p}<$ 0.05 was considered significant.

\section{Results}

Mesenchymal cells acquire TISC characteristics post-EMT In a previous report, we established a model of EMT using liver cancer cell lines derived from $\mathrm{Pten}^{-/}$mice [37]. In this model, we transplanted epithelial liver cancer cells, and from the resulting tumors, harvested epithelial and mesenchymal cells. The epithelial tumor cells were identical to parent cells, labeled P2-Epithelial (P2E), and the mesenchymal, fibroblastoid cells, were labeled P2-Mesenchymal (P2M) (Figure 1A). Both epithelial and mesenchymal cells demonstrated $\mathrm{Pten}^{-/-}$ genotype [37]. In support of the EMT-metastasis paradigm, mesenchymal cells demonstrated significant metastatic potential [37]. To confirm the persistence of epithelial and mesenchymal phenotypes, we analyzed the expression of key EMT genes and migratory/invasion in vitro. The mesenchymal cells demonstrate loss of E- 


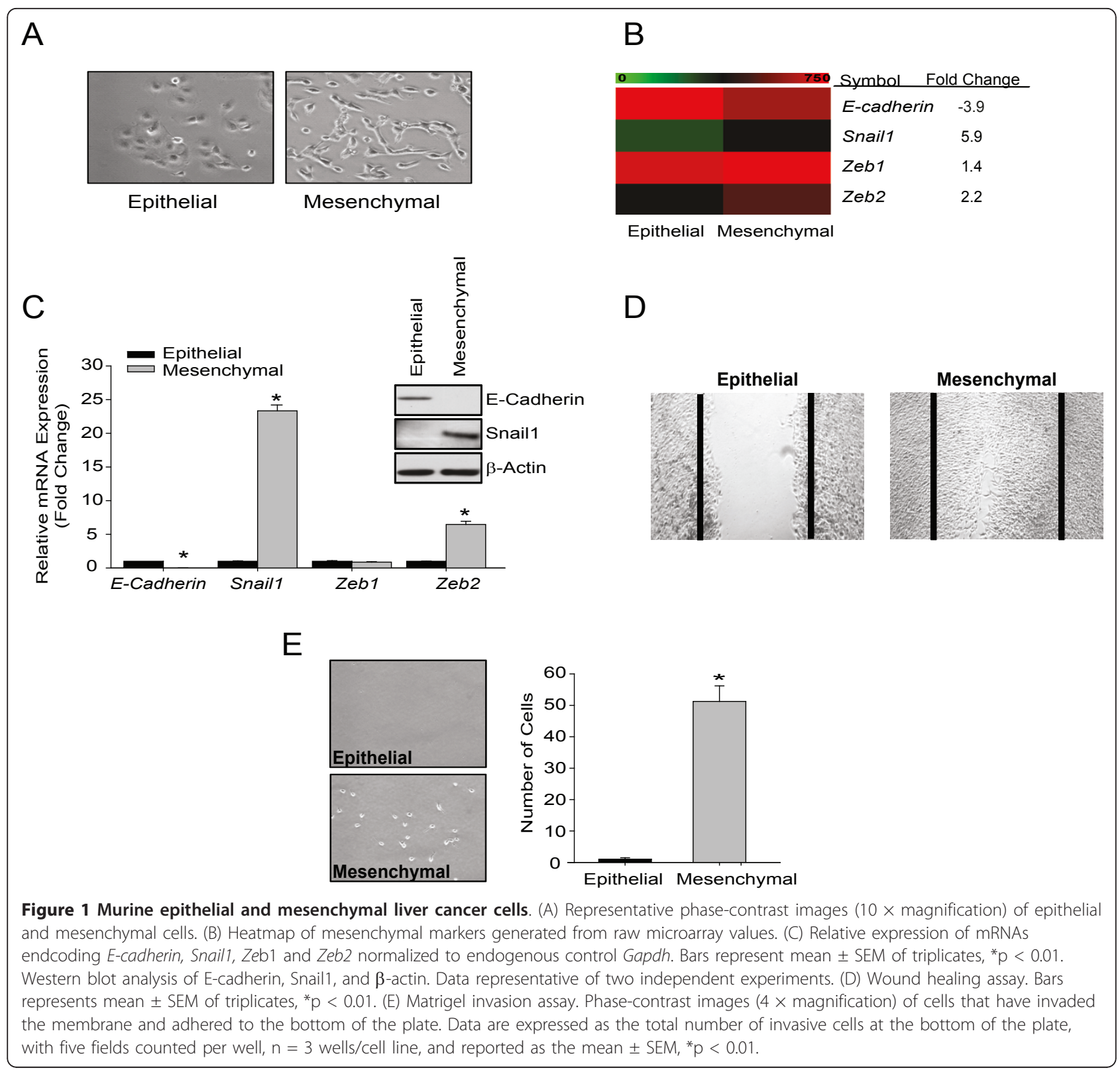

cadherin, gain of E-box transcription repressors Snail1 and Zeb2, significant migration in wound assay, and increased invasion through Matrigel pores compared to epithelial cells (Figure 1B-E).

In mesenchymal cells, transcriptome profiling demonstrated increased expression of multiple liver TISC markers (Figure 2A). Real-time PCR validated up-regulated Nanog, Oct-4, CD44, and EpCam (Figure 2B). Although CD133 is a strong TISC marker in previous reports, the mesenchymal cells have no detectable CD133 expression, making comparative analysis impossible. In terms of self-renewal assay, the mesenchymal cells were able to form large tumor-spheres in low adherent plates (Figure $2 \mathrm{C}$ ). Increased stem cell markers and tumor-sphere formation indicates that the mesenchymal cells have a TISC phenotype.

Resistance to chemotherapy is linked to cell proliferation To test the hypothesis that mesenchymal cells are resistant to chemotherapy, a TISC feature, cells were treated with doxorubicin and 5'Fluorouracil. The mesenchymal cells demonstrate increased sensitivity to genotoxic agents compared to epithelial cells (Figure 3A-B). In terms of cell cycle progression, the mesenchymal cells are highly proliferative compared to the epithelial cells (Figure 3E). Thus, we conclude that resistance to chemotherapy is linked to the level of cell proliferation, not mesenchymal status, consistent with the mechanism of 


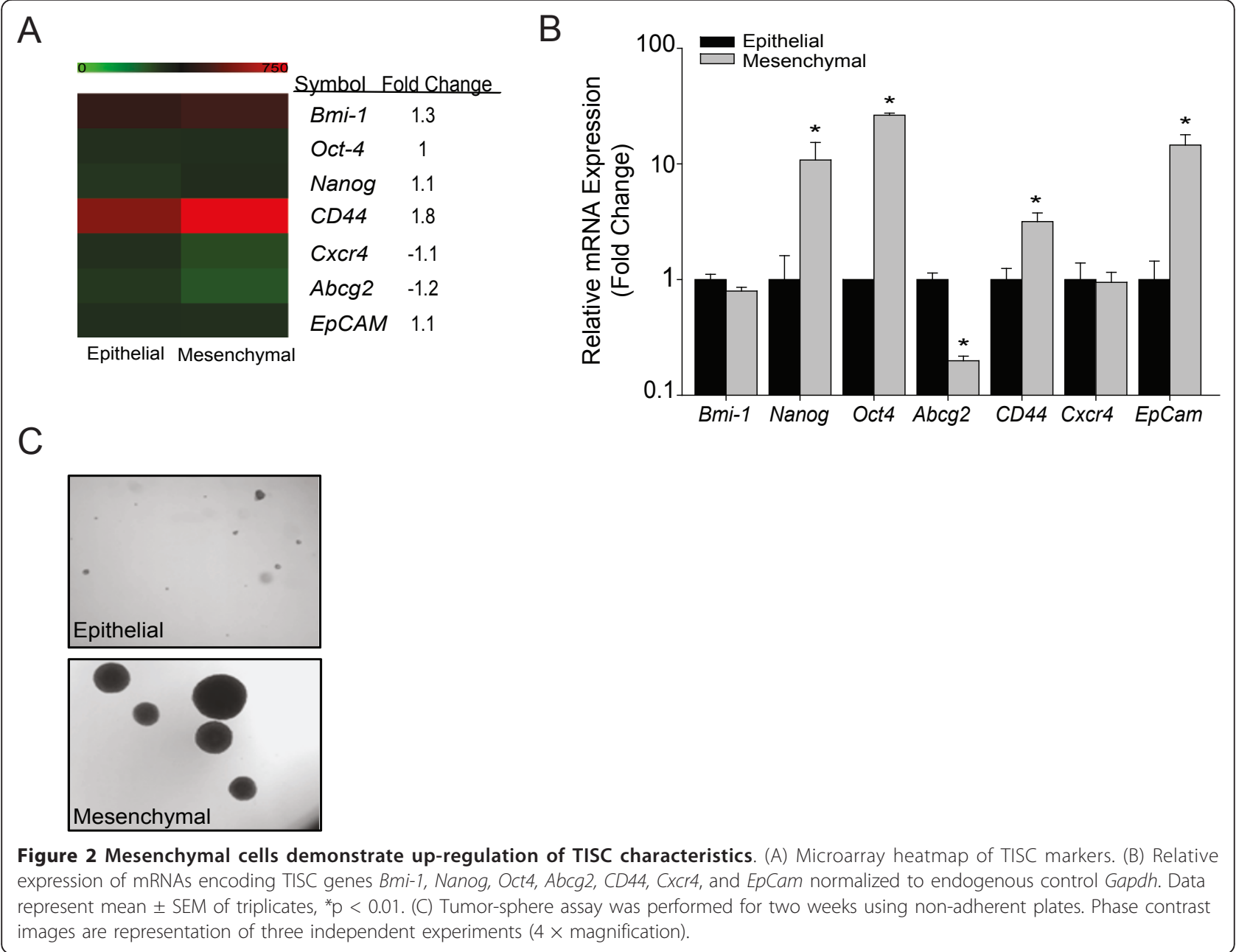

action of cytotoxic agents. In addition to rate of proliferation, $A b c g 2$ expression correlated with chemotherapy resistance (Figure $3 \mathrm{~A} \& 3 \mathrm{~B}, 2 \mathrm{~B}$ ), indicating that drug resistance may be dependent on the ATP-binding cassette expression as a mechanism of drug efflux. ATPbinding cassette efflux has been highly correlated to epithelial phenotype liver TISCs [14,42].

In addition to resistance to genotoxic agents, we assessed whether the mesenchymal cells are resistant to TRAIL-induced and TGF $\beta$-induced apoptosis. Although there was no significant difference in response to TRAIL stimulation (Figure 3C), the mesenchymal cells demonstrate resistance to TGF $\beta$-induced apoptosis (Figure 3D), a characteristic of TISCs [40].

\section{TGF $\beta$-induced EMT results in TISC characteristics}

During later stages of disease, TGF $\beta$ induces EMT and contributes to disease progression $[15,43]$. After TGF $\beta$ stimulation, epithelial cells undergo a morphological change from cuboidal to fibroblastic-like cells (Figure $4 \mathrm{~A})$. In addition to morphology change, TGF $\beta$ treatment resulted in increased cell migration and the formation of larger spheroids in low adherent plates (Figure 4B \&4C. This TGF $\beta$-induced change was associated with typical EMT characteristics, including decreased E-cadherin and increased Snail1 and Nanog (Figure 4D \&4E).

\section{Inhibition of Snail1 blocks TISC characteristics}

In HCC, a TISC phenotype with Snail1 over-expression is associated with poor prognosis [21]. To test the specific role of Snail1 in up-regulating TISC characteristics, we utilized siRNA to knock down Snail1 in mesenchymal cells. After Snail1 siRNA treatment, TISC markers Nanog and CD44 decreased significantly (Figure 5A), which was associated with decreased spheroid formation (Figure 5B) and decreased migration (Figure 5C).

TGF $\beta$ regulates Snail and Nanog through Smad signaling The primary mechanism of TGF $\beta$-induced EMT is through Smad-dependent signaling. Following activation of TGF $\beta$ receptors, Smad2 and Smad3 are 


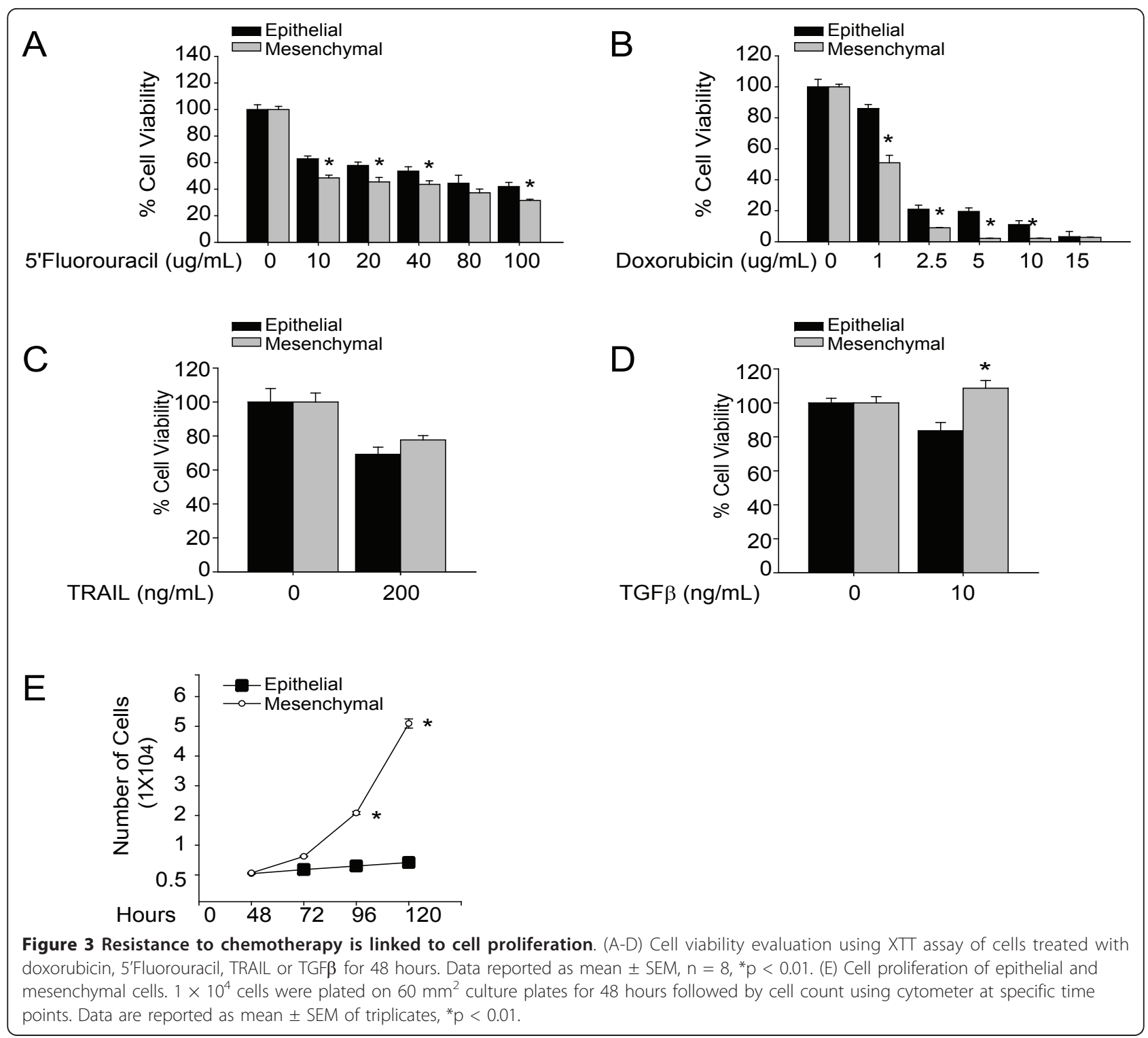

phosphorylated and form the Smad2/3/4 heterocomplex, which translocates to the nucleus to regulate Snail1 transcription $[19,27,44]$. After TGF $\beta$ stimulation in epithelial cells, Snail1 increased (Figure 4D). In order to confirm that TGF $\beta$ induces Snail1 through Smaddependent pathways in our model, we utilized inhibitory Smads, Smad7 and dominant-negative Smad3 ( $\Delta$ Smad3), which block heterocomplex formation. Epithelial cells were transfected with $S \operatorname{mad} 7$ or $\Delta \mathrm{Smad} 3$ vectors 24 hours prior to TGF $\beta$ stimulation. qPCR and western blot analysis demonstrated that inhibitory Smads significantly attenuated TGF $\beta$-induced Snail1 up-regulation (Figure 6A \&6B).

TGF $\beta$ regulates Nanog promoter activity through Smad signaling in human embryonic stem cells [31]. To confirm that TGF $\beta$ can induce Nanog promoter activity in our model, epithelial cells were co-transfected with Nanog-Luc and Smad7 or $\Delta$ Smad3 vectors. Following TGF $\beta$ stimulation, Nanog-Luc activity was significantly attenuated by inhibitory Smads (Figure 6C \&6D), indicating that TGF $\beta$ stimulates Nanog promoter activity through Smad-dependent signaling.

\section{Snail1 directly regulates Nanog promoter}

After transient knock-down of Snail1, Nanog expression is decreased, indicating that Snail1 directly regulates TISC genes in mesenchymal cells (Figure 3B). To further investigate this Snail1-driven TISC expression profile, we established stable Snail1 knock-down in mesenchymal-Snail1-shRNA cells (Figure 7A). In these mesenchymal-Snail1-shRNA cells, down regulation of Snail1 corresponded to decreased Nanog promoter 


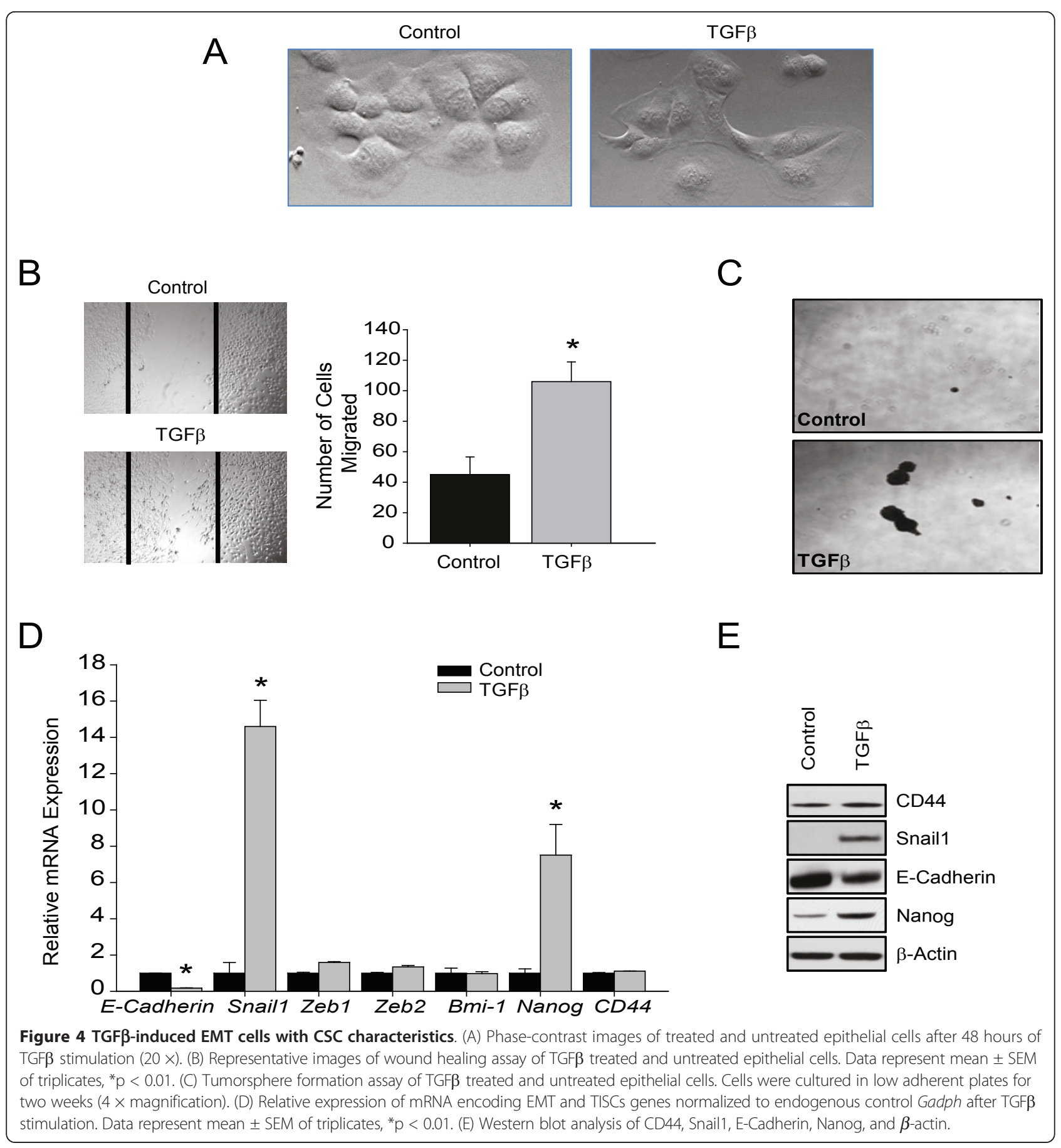

activity and decreased Nanog and CD44 expression (Figure 7A \&7B).

Inhibition of Snail1 results in decreased tumor growth in vivo

As demonstrated, Snail1 is a key regulator of TISC characteristics in vitro. To investigate the role of Snail1 in tumor initiation, we inoculated $1 \times 10^{4}$ mesenchymal-Snail1-
shRNA cells into nude mice. The mesenchymal-Snail1shRNA cells demonstrate reduced in tumor growth compared to control mesenchymal cells. Analysis of tumors demonstrates that Snail1 expression was down-regulated in $1 \times 10^{4}$ cell initiated tumors from mesenchymal-Snail1siR cells (Figure 7C). However, tumor initiation was not affected by Snail1 suppression, as evidence by all inoculations forming tumors, even in Snail1 inhibited cells. 


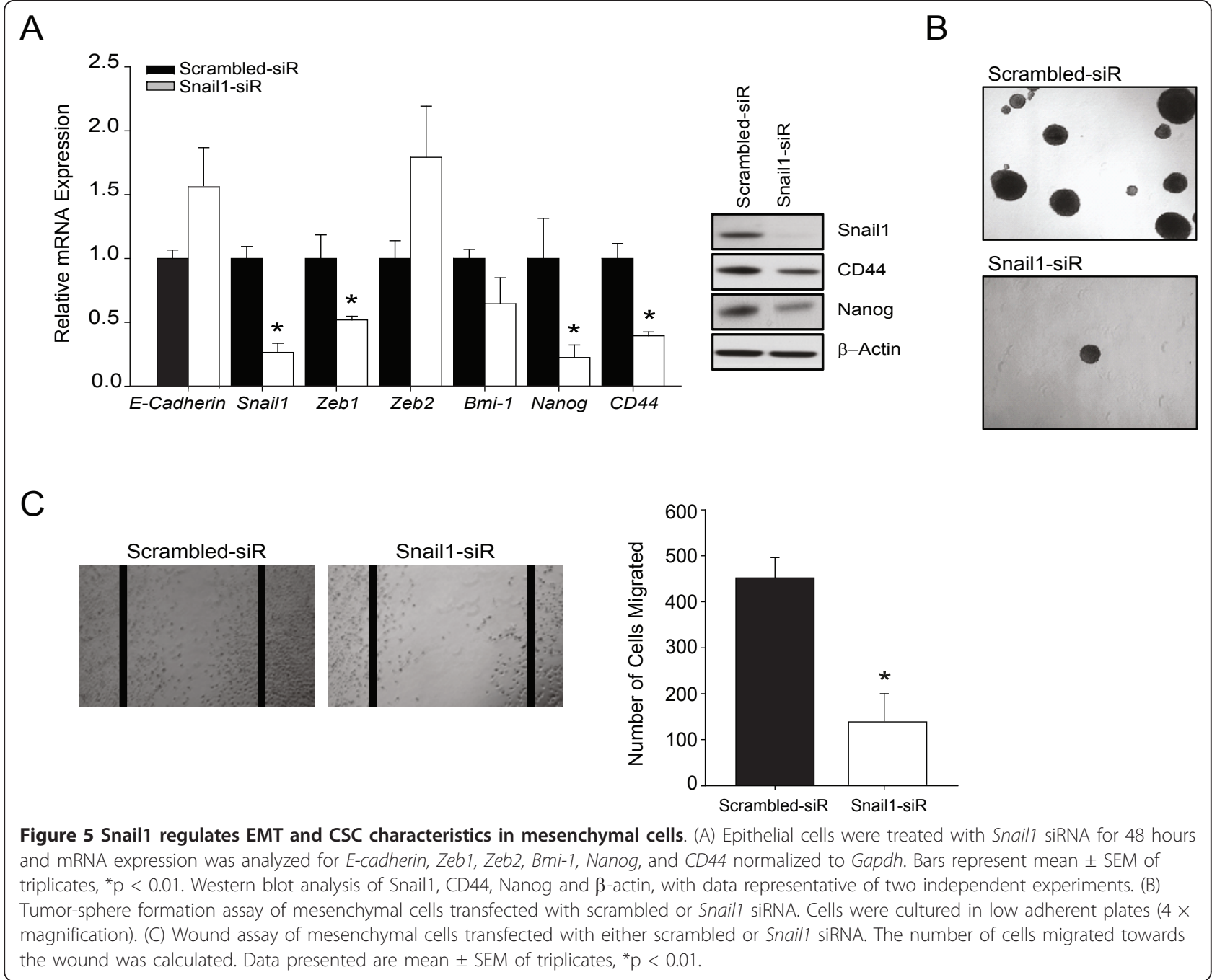

Epithelial and mesenchymal differences in human HCC In order to investigate SNAIL1 and NANOG expression in human HCC cells, we utilized Huh7 and MHCC97-L cells. Huh7 cells have been described to be epithelial whereas MHCC97-L cells are mesenchymal with metastatic potential $[38,39]$. Accordingly, MHCC97-L cells demonstrate significant migration and invasion, increased expression of SNAIL1, NANOG and decreased expression of E-Cadherin (Figure 8B-D). Mesenchymal MHCC97-L cells also demonstrate TISC characteristics including increased NANOG, BMI-1, CD44 and OCT4 mRNA expression as well as increased tumorsphere formation (Figure 8E \&8F).

\section{Discussion}

Although liver transplantation has significantly improved survival in patients with early stage $\mathrm{HCC}$, the prognosis for late stage HCC remains poor [45]. Causes of poor prognosis in late stage disease include invasive/ metastatic disease and tumor recurrence after treatment. In breast cancer, EMT has been linked to TISC characteristics and resistant disease. Although this link between EMT and TISCs has been established in other cancers, including breast, prostate, nasopharyngeal, and colon cancer, this relationship has yet to be defined in HCC $[17,22,46]$. One potential link between EMT and TISCs in liver cancer is TGF $\beta$.

TGF $\beta$ has a dual role in HCC either as a tumor suppressor in early stages or tumor promoter in later stages $[15,43]$. One of the mechanisms of early neoplastic transformation is through the evasion of cytostatic effects of TGF $\beta$ [43]. During the late stages of HCC tumorgenesis, TGF $\beta$ stimulates cellular invasion through the EMT program [44].

TGF $\beta$ induces EMT through Snail1, which represses E-cadherin by binding to E-box promoter elements $[18,19,47]$. In cancer patients, an EMT-phenotype transcriptome profile, with increased Snaill expression, 


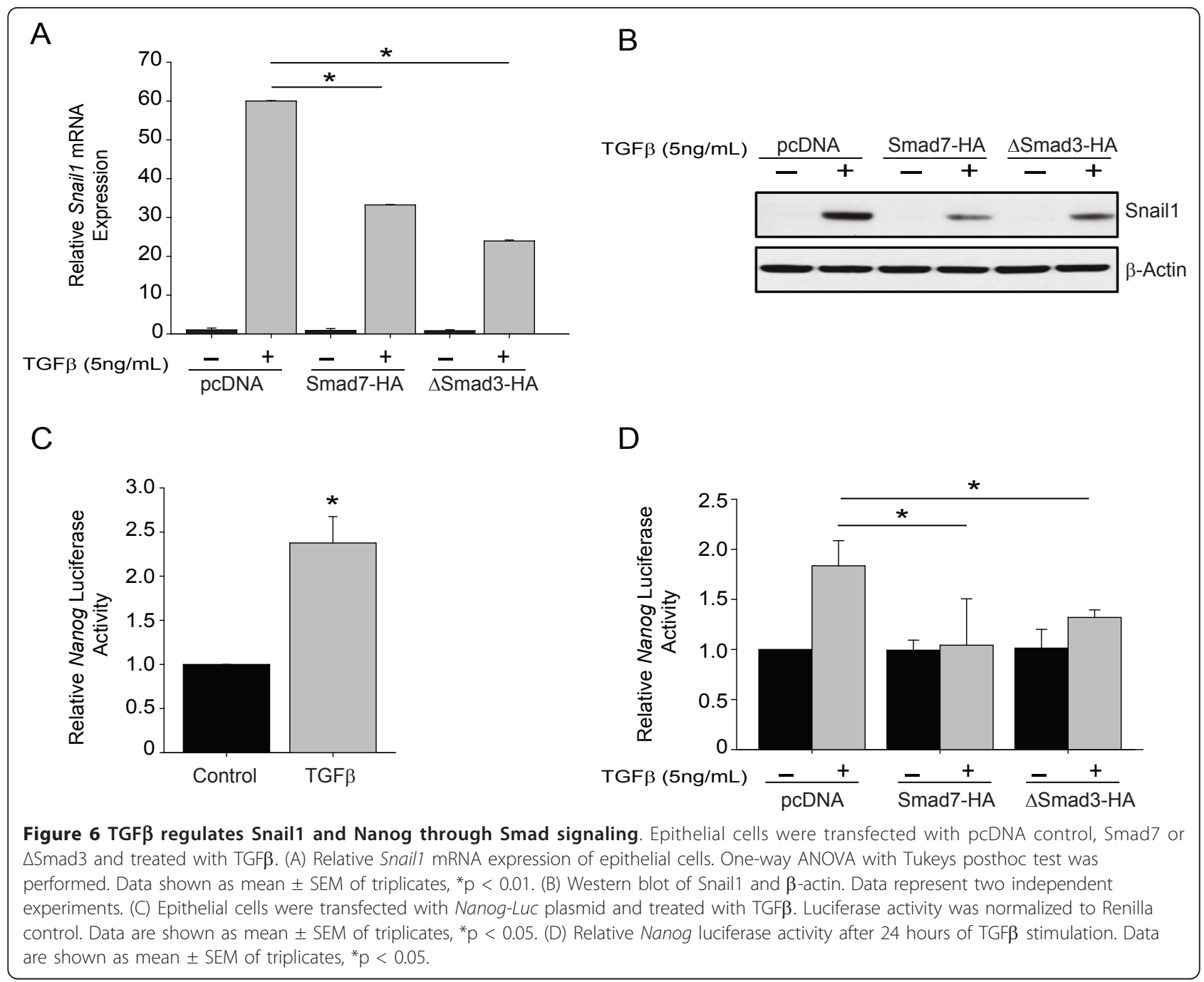

correlates with invasive tumors $[21,48,49]$. In this report, TGF $\beta$ stimulation of epithelial liver cancer cells results in a mesenchymal phenotype with fibroblastoid appearance, loss of E-cadherin, increased invasion and migration, and an up-regulation of Snail1. In addition, TGF $\beta$ treatment induces a TISC phenotype in epithelial cells. Although TGF $\beta$-induced EMT generates TISC characteristics $[17,22]$, the underlying mechanism has not yet been elucidated. Based on our results, we hypothesize that these TISC characteristics are Snail1 dependent. Inhibition of Snail1 causes the down-regulation of Nanog, Bmi-1 and CD44, loss of a migration and selfrenewal as evidenced by decreased tumor-sphere formation.

Another key regulatory signaling pathway known to induce EMT in liver cells is the Hedgehog (Hh) signaling pathway. Hh promotes EMT in response to chronic liver injury [50]. In addition, Hh signaling has been suggested to play an important role in the maintenance of
TISCs, and BMI-1, the polycomb group protein, may directly mediate Hh signaling in order to confer a selfrenewal capacity in TISCs $[10,46,51]$. However, within our system, we were unable to see significant differences of BMI-1 between epithelial and mesenchymal cells.

TGF $\beta$ also directly controls Nanog in human embryonic stem cells [31]. Nanog is a key transcription factor that regulates self-renewal in stem cells [4,52]. Recent studies demonstrate that Nanog promotes TISC characteristics, and the down regulation of Nanog inhibits sphere formation and tumor development $[4,34,35,53]$. In this report, Nanog is up-regulated by TGF $\beta$ through Smad signaling. In addition, Snail1 directly regulates Nanog promoter activity.

TISCs are proposed to initiate tumors. In our model, liver cancer cells with a mesenchymal phenotype demonstrate TISCs characteristics, including tumorsphere formation and increased expression of CD44 and Nanog. We further investigated epithelial and 
A

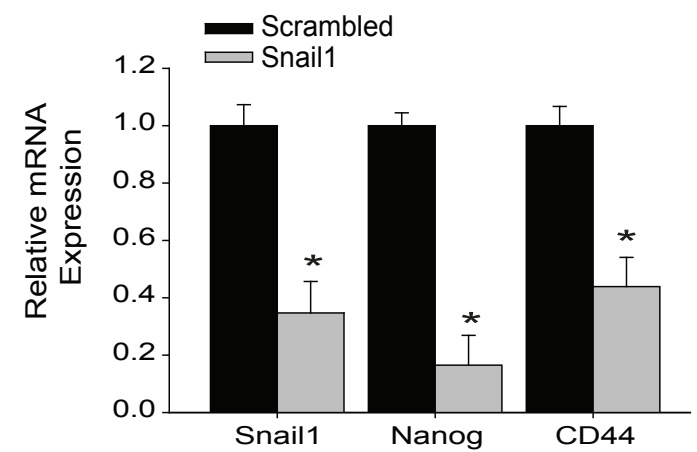

C
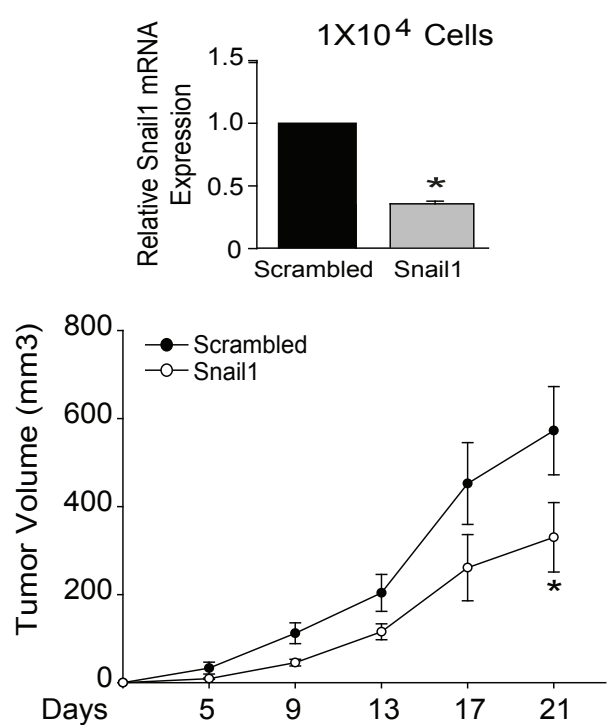

B

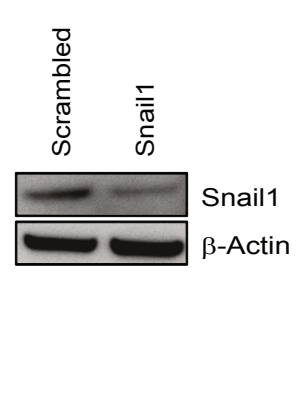

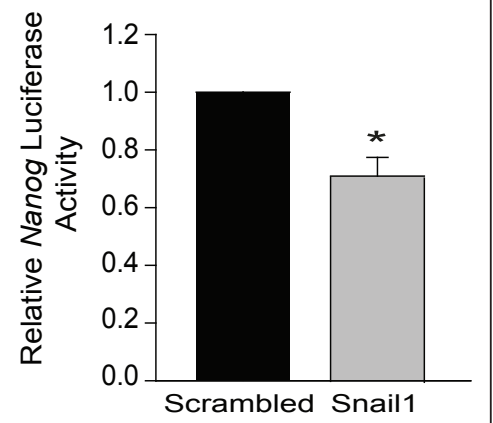
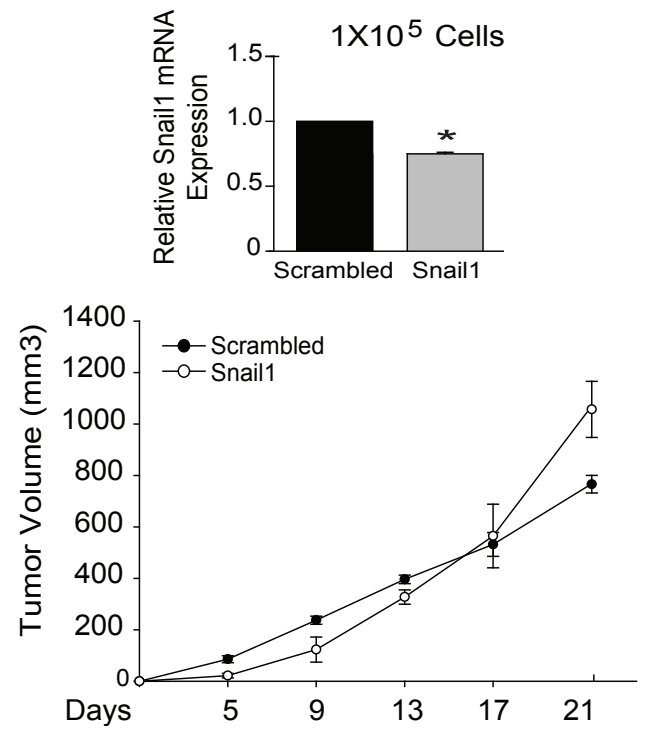

Figure 7 Repression of Snail1 attenuates Nanog promoter activity and tumor proliferation. (A) Relative gene expression of Snail1, Nanog, and CD44 of mesenchymal-scrambled-shRNA compared to mesenchymal-Snail1-shRNA cells. Bars represent mean \pm SEM of triplicates, ${ }^{*} p<0.05$. Western blot of Snail1 and $\beta$-actin, with blots representative of two independent experiments. (B) Inhibition of Snail1 reduces Nanog luciferase activity. Data presented are shown as mean \pm SEM of three independent experiments, ${ }^{*} p<0.05$. (C) Tumors of indicated number of cells of mesenchymal-scrambled-shRNA or mesenchymal-Snail1-shRNA knock-down cells. Tumor volume reported as mean \pm SEM, ${ }^{*} \mathrm{p}<0.05$; $\mathrm{N}=4$ / group. Relative Snail1 mRNA expression of tumor tissues. Data presented are reported as mean \pm SEM of all Scrambled and Snail 1 tumor tissues, ${ }^{*} p<0.05 ; N=4$ /group.

mesenchymal phenotypes in human HCC, Huh7 and MHCC97-L cells. Accordingly, Huh7 cells follow an epithelial phenotype whereas MHCC97-L cells are more mesenchymal demonstrating increased Snail1, Zeb1, Zeb2 mRNA expression, decreased E-cadherin expression, increased migration/invasion and increased tumorsphere formation [38].

In our murine system, Snail1 inhibition resulted in loss of tumor-sphere formation, decreased expression of CD44 and Nanog, and decreased tumor growth. According to our in vitro results, Snaill clearly regulates TISC characteristics. However, the loss of Snail1 is not sufficient to inhibit tumor initiation, as evidenced by in vivo results. These findings are not un-expected in that the proposed TISC-driven tumor initiation is an early event in tumorigenesis, and cells that acquire TISC characteristics after EMT are a late event in tumor progression. In addition, Snail 1 is one of many regulators of EMT, and thus manipulation of multiple factors may be required to fully inhibit tumor initiation.

\section{Conclusion}

In summary, we demonstrated that TGF $\beta$ induces EMT and TISC characteristics through the up-regulation of Snail1 and Nanog. In addition, Snail1 directly regulates Nanog promoter activity. Notably, expression of both 


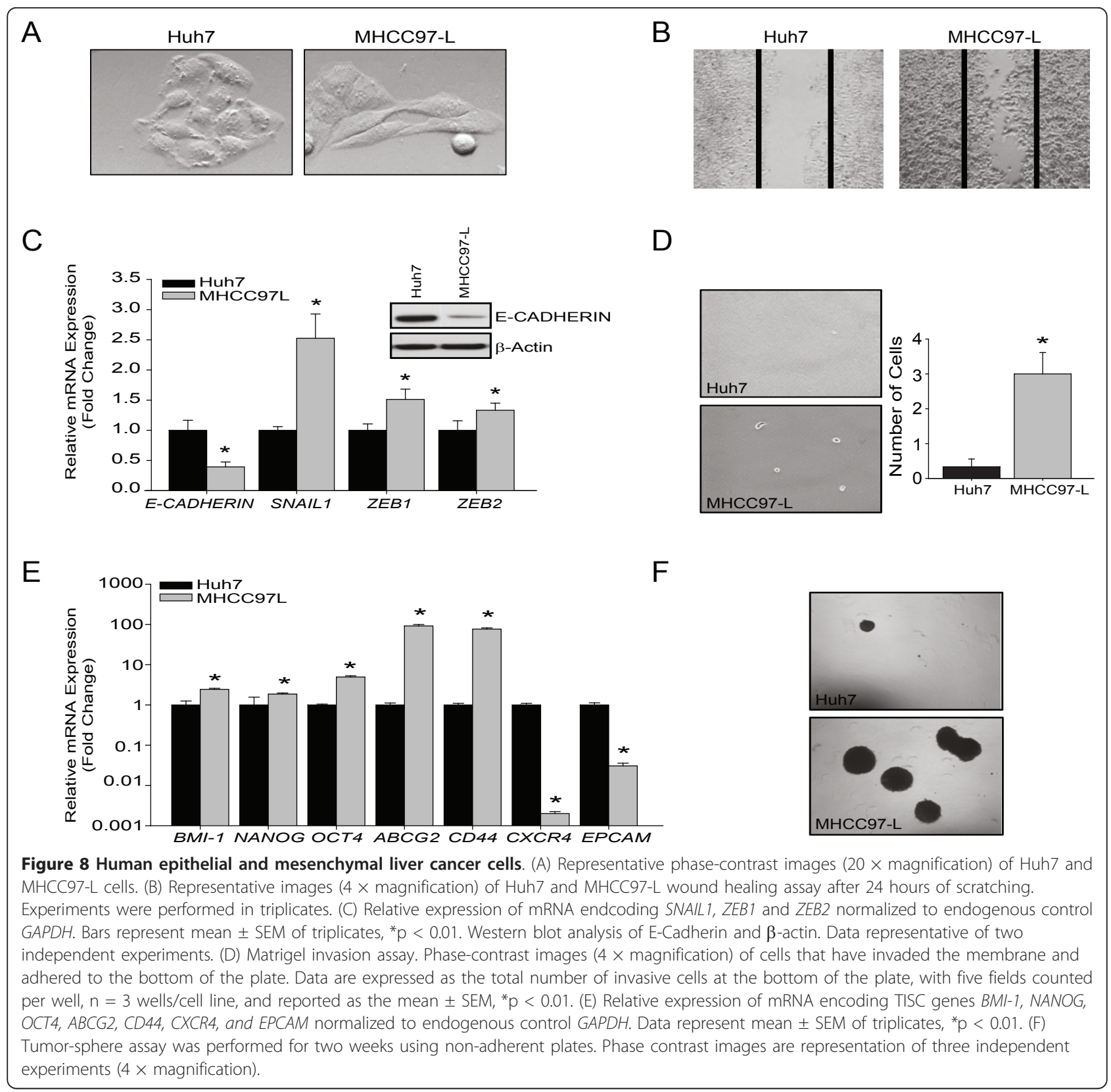

SNAIL1 and NANOG is higher in human mesenchymal cells. Inhibition of Snail1 alone is not sufficient to inhibit tumor initiation, but does result in reduction of tumor growth in vivo.

\section{List of abbreviations}

TISCs: Tumor initiating stem-like cells; HCC: hepatocellular carcinoma; EMT: epithelial-mesenchymal-transition; TGF $\beta$ : transforming growth factor- $\beta$; FBS: fetal bovine serum.

\section{Acknowledgements}

This publication was made possible by generous support from the National Institute of Health, K08DK080928 and R03DK088013 (CBR); the American
Cancer Society, Research Scholar Award, RSG-10-073-01-TBG (CBR); and the Children's Miracle Network (CBR).

\section{Authors' contributions}

HD carried out the molecular and in vivo studies and drafted the manuscript. WD assisted in molecular and in vivo studies and manuscript preparation. DE participated in molecular in vitro studies. CBR conceived of the study, and participated in its design and coordination and helped to draft the manuscript. All authors read and approved the final manuscript.

\section{Competing interests}

Dr. Rountree reports research support of less than $\$ 10,000$ from Bayer Pharmaceuticals for un-related studies. Authors Dang, Ding, and Emerson report no competing interests.

Received: 27 June 2011 Accepted: 19 September 2011 Published: 19 September 2011 
References

1. Clarke MF, Dick JE, Dirks PB, Eaves CJ, Jamieson CH, Jones DL, Visvader J, Weissman IL, Wahl GM: Cancer stem cells-perspectives on current status and future directions: AACR Workshop on cancer stem cells. Cancer Res 2006, 66:9339-9344.

2. Reya T, Morrison SJ, Clarke MF, Weissman IL: Stem cells, cancer, and cancer stem cells. Nature 2001, 414:105-111.

3. Lobo NA, Shimono Y, Qian D, Clarke MF: The biology of cancer stem cells. Annu Rev Cell Dev Biol 2007, 23:675-699.

4. Jeter CR, Liu B, Liu X, Chen X, Liu C, Calhoun-Davis T, Repass J, Zaehres H, Shen JJ, Tang DG: NANOG promotes cancer stem cell characteristics and prostate cancer resistance to androgen deprivation. Oncogene 2011.

5. Hu T, Liu S, Breiter DR, Wang F, Tang Y, Sun S: Octamer 4 small interfering RNA results in cancer stem cell-like cell apoptosis. Cancer Res 2008, 68:6533-6540

6. Lapidot T, Sirard C, Vormoor J, Murdoch B, Hoang T, Caceres-Cortes J, Minden M, Paterson B, Caligiuri MA, Dick JE: A cell initiating human acute myeloid leukaemia after transplantation into SCID mice. Nature 1994, 367:645-648

7. Bonnet D, Dick JE: Human acute myeloid leukemia is organized as a hierarchy that originates from a primitive hematopoietic cell. Nat Med 1997, 3:730-737.

8. Ma S, Chan KW, Hu L, Lee TK, Wo JY, Ng IO, Zheng BJ, Guan XY: Identification and characterization of tumorigenic liver cancer stem/ progenitor cells. Gastroenterology 2007, 132:2542-2556.

9. Yin $\mathrm{S}, \mathrm{Li}$ J, Hu C, Chen X, Yao M, Yan M, Jiang G, Ge C, Xie H, Wan D, et al: CD133 positive hepatocellular carcinoma cells possess high capacity for tumorigenicity. Int J Cancer 2007, 120:1444-1450.

10. Rangwala F, Omenetti A, Diehl AM: Cancer stem cells: repair gone awry? J Oncol 2011, 2011:465343

11. Tang Y, Kitisin K, Jogunoori W, Li C, Deng CX, Mueller SC, Ressom HW, Rashid A, He AR, Mendelson JS, et al: Progenitor/stem cells give rise to liver cancer due to aberrant TGF-beta and IL-6 signaling. Proc Natl Acad Sci USA 2008, 105:2445-2450.

12. Yamashita T, Forgues M, Wang W, Kim JW, Ye Q, Jia H, Budhu A, Zanetti KA, Chen Y, Qin LX, et al: EpCAM and alpha-fetoprotein expression defines novel prognostic subtypes of hepatocellular carcinoma. Cancer Res 2008, 68:1451-1461.

13. Thorgeirsson SS, Grisham JW: Molecular pathogenesis of human hepatocellular carcinoma. Nat Genet 2002, 31:339-346

14. Lee JS, Heo J, Libbrecht L, Chu IS, Kaposi-Novak P, Calvisi DF, Mikaelyan A, Roberts $L R$, Demetris $A J$, Sun $Z$, et al: A novel prognostic subtype of human hepatocellular carcinoma derived from hepatic progenitor cells. Nat Med 2006, 12:410-416.

15. Yao Z, Mishra L: Cancer stem cells and hepatocellular carcinoma. Cancer Biol Ther 2009, 8:1691-1698.

16. Yang J, Weinberg RA: Epithelial-mesenchymal transition: at the crossroads of development and tumor metastasis. Dev Cell 2008, 14:818-829.

17. Mani SA, Guo W, Liao MJ, Eaton EN, Ayyanan A, Zhou AY, Brooks M, Reinhard F, Zhang CC, Shipitsin M, et al: The epithelial-mesenchymal transition generates cells with properties of stem cells. Cell 2008, 133:704-715

18. Thiery JP, Acloque H, Huang RY, Nieto MA: Epithelial-mesenchymal transitions in development and disease. Cell 2009, 139:871-890.

19. Thiery JP: Epithelial-mesenchymal transitions in tumour progression. Nat Rev Cancer 2002, 2:442-454.

20. Polyak K, Weinberg RA: Transitions between epithelial and mesenchymal states: acquisition of malignant and stem cell traits. Nat Rev Cancer 2009, 9:265-273.

21. Yang MH, Chen CL, Chau GY, Chiou SH, Su CW, Chou TY, Peng WL, Wu JC: Comprehensive analysis of the independent effect of twist and snail in promoting metastasis of hepatocellular carcinoma. Hepatology 2009, 50:1464-1474.

22. Morel AP, Lievre M, Thomas C, Hinkal G, Ansieau S, Puisieux A: Generation of breast cancer stem cells through epithelial-mesenchymal transition. PLoS One 2008, 3:e2888.

23. Amin R, Mishra L: Liver stem cells and tgf-Beta in hepatic carcinogenesis. Gastrointest Cancer Res 2008, 2:S27-30.

24. Roberts $A B$, Wakefield $L M$ : The two faces of transforming growth factor beta in carcinogenesis. Proc Natl Acad Sci USA 2003, 100:8621-8623.
25. Abou-Shady M, Baer HU, Friess H, Berberat P, Zimmermann A, Graber H, Gold LI, Korc M, Buchler MW: Transforming growth factor betas and their signaling receptors in human hepatocellular carcinoma. Am J Surg 1999, 177:209-215.

26. Mishra L, Shetty K, Tang Y, Stuart A, Byers SW: The role of TGF-beta and Wnt signaling in gastrointestinal stem cells and cancer. Oncogene 2005, 24:5775-5789.

27. Peinado $H$, Olmeda D, Cano A: Snail, Zeb and bHLH factors in tumour progression: an alliance against the epithelial phenotype? Nat Rev Cancer 2007, 7:415-428.

28. Thenappan A, Li Y, Kitisin K, Rashid A, Shetty K, Johnson L, Mishra L: Role of transforming growth factor beta signaling and expansion of progenitor cells in regenerating liver. Hepatology 2010, 51:1373-1382.

29. Mishra L, Derynck R, Mishra B: Transforming growth factor-beta signaling in stem cells and cancer. Science 2005, 310:68-71.

30. Tang Y, Katuri V, Dillner A, Mishra B, Deng CX, Mishra L: Disruption of transforming growth factor-beta signaling in ELF beta-spectrin-deficient mice. Science 2003, 299:574-577.

31. Xu RH, Sampsell-Barron TL, Gu F, Root S, Peck RM, Pan G, Yu J, AntosiewiczBourget J, Tian S, Stewart R, Thomson JA: NANOG is a direct target of TGFbeta/activin-mediated SMAD signaling in human ESCs. Cell Stem Cell 2008, 3:196-206.

32. Greber B, Lehrach $\mathrm{H}$, Adjaye J: Control of early fate decisions in human ES cells by distinct states of TGFbeta pathway activity. Stem Cells Dev 2008 17:1065-1077.

33. Chiou SH, Wang ML, Chou YT, Chen CJ, Hong CF, Hsieh WJ, Chang HT, Chen YS, Lin TW, Hsu HS, Wu CW: Coexpression of Oct4 and Nanog enhances malignancy in lung adenocarcinoma by inducing cancer stem cell-like properties and epithelial-mesenchymal transdifferentiation. Cancer Res 2010, 70:10433-10444.

34. Jeter CR, Badeaux M, Choy G, Chandra D, Patrawala L, Liu C, CalhounDavis T, Zaehres H, Daley GQ, Tang DG: Functional evidence that the selfrenewal gene NANOG regulates human tumor development. Stem Cells 2009, 27:993-1005.

35. Meng HM, Zheng P, Wang XY, Liu C, Sui HM, Wu SJ, Zhou J, Ding YQ, Li JM: Overexpression of nanog predicts tumor progression and poor prognosis in colorectal cancer. Cancer Biol Ther 2010, 9.

36. You H, Ding W, Rountree CB: Epigenetic regulation of cancer stem cell marker CD133 by transforming growth factor-beta. Hepatology 2010 51:1635-1644.

37. Ding W, You H, Dang H, Leblanc F, Galicia V, Lu SC, Stiles B, Rountree CB: Epithelial-to-mesenchymal transition of murine liver tumor cells promotes invasion. Hepatology 2010, 52:945-953.

38. You H, Ding W, Dang H, Jiang Y, Rountree CB: C-Met represents a potential therapeutic target for personalized treatment in hepatocellular carcinoma. Hepatology 2011

39. Li Y, Tang ZY, Ye SL, Liu YK, Chen J, Xue Q, Gao DM, Bao WH: Establishment of cell clones with different metastatic potential from the metastatic hepatocellular carcinoma cell line MHCC97. World J Gastroenterol 2001, 7:630-636

40. Ding W, Mouzaki M, You H, Laird JC, Mato J, Lu SC, Rountree CB: CD133+ liver cancer stem cells from methionine adenosyl transferase $1 \mathrm{~A}$ deficient mice demonstrate resistance to transforming growth factor (TGF)-beta-induced apoptosis. Hepatology 2009, 49:1277-1286.

41. Rountree CB, Van Kirk CA, You H, Ding W, Dang H, Vanguilder HD, Freeman WM: Clinical application for the preservation of phosphoproteins through in-situ tissue stabilization. Proteome Sci 2010, 8:61.

42. Zen Y, Fujii T, Yoshikawa S, Takamura H, Tani T, Ohta T, Nakanuma Y: Histological and culture studies with respect to ABCG2 expression support the existence of a cancer cell hierarchy in human hepatocellular carcinoma. Am J Pathol 2007, 170:1750-1762.

43. Akhurst RJ, Derynck R: TGF-beta signaling in cancer-a double-edged sword. Trends Cell Biol 2001, 11:S44-51.

44. Xu J, Lamouille S, Derynck R: TGF-beta-induced epithelial to mesenchymal transition. Cell Res 2009, 19:156-172.

45. El-Serag HB: Hepatocellular carcinoma: an epidemiologic view. J Clin Gastroenterol 2002, 35:S72-78

46. Song $L B$, Li J, Liao WT, Feng Y, Yu CP, Hu LJ, Kong QL, Xu LH, Zhang X, Liu WL, et al: The polycomb group protein Bmi-1 represses the tumor suppressor PTEN and induces epithelial-mesenchymal transition in human nasopharyngeal epithelial cells. J Clin Invest 2009, 119:3626-3636. 
47. Cano A, Perez-Moreno MA, Rodrigo I, Locascio A, Blanco MJ, del Barrio MG, Portillo F, Nieto MA: The transcription factor snail controls epithelialmesenchymal transitions by repressing E-cadherin expression. Nat Cell Biol 2000, 2:76-83.

48. Dooley S, Hamzavi J, Ciuclan L, Godoy P, Ilkavets I, Ehnert S, Ueberham E, Gebhardt R, Kanzler S, Geier A, et al: Hepatocyte-specific Smad7 expression attenuates TGF-beta-mediated fibrogenesis and protects against liver damage. Gastroenterology 2008, 135:642-659.

49. Coulouarn C, Factor VM, Thorgeirsson SS: Transforming growth factor-beta gene expression signature in mouse hepatocytes predicts clinical outcome in human cancer. Hepatology 2008, 47:2059-2067.

50. Omenetti A, Porrello A, Jung Y, Yang L, Popov Y, Choi SS, Witek RP, Alpini $G$, Venter J, Vandongen $H M$, et al: Hedgehog signaling regulates epithelial-mesenchymal transition during biliary fibrosis in rodents and humans. J Clin Invest 2008, 118:3331-3342.

51. Liu S, Dontu G, Mantle ID, Patel S, Ahn NS, Jackson KW, Suri P, Wicha MS: Hedgehog signaling and Bmi-1 regulate self-renewal of normal and malignant human mammary stem cells. Cancer Res 2006, 66:6063-6071.

52. Silva J, Nichols J, Theunissen TW, Guo G, van Oosten AL, Barrandon O, Wray J, Yamanaka S, Chambers I, Smith A: Nanog is the gateway to the pluripotent ground state. Cell 2009, 138:722-737.

53. Chen C, Wei Y, Hummel M, Hoffmann TK, Gross M, Kaufmann AM, Albers AE: Evidence for epithelial-mesenchymal transition in cancer stem cells of head and neck squamous cell carcinoma. PLoS One 2011, 6: e16466.

\section{Pre-publication history}

The pre-publication history for this paper can be accessed here: http://www.biomedcentral.com/1471-2407/11/396/prepub

doi:10.1186/1471-2407-11-396

Cite this article as: Dang et al:. Snail1 induces epithelial-tomesenchymal transition and tumor initiating stem cell characteristics. BMC Cancer 2011 11:396.

\section{Submit your next manuscript to BioMed Central and take full advantage of:}

- Convenient online submission

- Thorough peer review

- No space constraints or color figure charges

- Immediate publication on acceptance

- Inclusion in PubMed, CAS, Scopus and Google Scholar

- Research which is freely available for redistribution

Submit your manuscript at www.biomedcentral.com/submit 